\title{
Getting closer by increasing distance: the dynamics of value creation spheres in health care logistics
}

\author{
Timo Pohjosenperä and Hanna Komulainen \\ Department of Marketing, Management and International Business, Oulu Business School, University of Oulu, Oulu, Finland
}

\begin{abstract}
Purpose - This paper aims to explore the dynamics of value co-creation in the context of health care logistics by focusing on the change in the value creation spheres of a logistics service provider and its customer organization.

Design/methodology/approach - The development of value co-creation between the two organizations was researched through a qualitative case study that focuses on a situation wherein the hospital's central warehouse was moved to a more distant location. Data consist of the interviews and focus group discussions of both nursing staff and logistics managers before and after the change. The empirical results are reflected to service and value co-creation literature as well as to existing knowledge about health care logistics.

Findings - The new situation compelled the counterparts to plan more structured logistics service procedures, as there was no longer any possibility for nursing staff to pick up urgently needed items from the central warehouse. This strengthened the role of the joint value creation sphere and made it more visible during the change.

Research limitations/implications - The study contributes to the evolving research on health care logistics and connects it to timely service value discussion. This paper proposes that as the physical distance of service facilities increases, the joint co-creation sphere, interestingly, gets widened during the change.

Practical implications - Managerially, the study provides implications for how to develop health-care material logistics to provide more value for both the logistics service providers and their customers.

Social implications - Understanding value co-creation in health care logistics services supports care organizations in developing their processes toward better care for the patients. Thus, health care logistics research facilitates societies and health-care systems to reach their goals in terms of better service and lower costs.
\end{abstract}

Originality/value - This study presents an up-to-date example of value co-creation in the scarcely researched context of health care logistics.

Keywords Health care, Logistics, Services, Value

Paper type Research paper

\section{Introduction}

For several years, we have been observing the organization and change in health-care material logistics in a hospital located in Finland. This university hospital has its own in-house logistics service provider (later referred to as the logistics unit) that takes care of purchasing, deliveries, warehousing, and service development activities. In 2017, the warehouse facilities moved to a different location, outside the hospital campus, causing longer transportation distances and potentially lower availability. This change has had a significant effect on the relationship between the logistics unit and the customer organization (later in the text, the customer, i.e. the nursing staff in clinics and departments in the hospital) and value cocreation activities between them. Thus, we became intrigued about whether the increasing physical distance influences value

The current issue and full text archive of this journal is available on Emerald Insight at: https://www.emerald.com/insight/0885-8624.htm

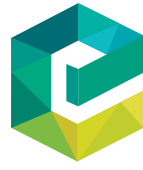

Journal of Business \& Industrial Marketing 35/12 (2020) 2039-2050

Emerald Publishing Limited [ISSN 0885-8624] [DOI 10.1108/JBIM-03-2019-0110] co-creation in the context of health care logistics and, if so, how and why.

Our interest in studying these questions has been vitalized by growing attention being paid towards researching and developing health care logistics by academics and practitioners in recent years (Ageron et al., 2018; Kumar et al., 2008; Volland et al., 2017). In fact, logistics has been identified as one of the most important means for managing health-care costs (de Vries and Huijsman, 2011), and it has been estimated that up to half of the logistics costs in hospitals can be eliminated by efficient logistics management (Poulin, 2003). Furthermore, health-care organizations are required to simultaneously reduce

(C) Timo Pohjosenperä and Hanna Komulainen. Published by Emerald Publishing Limited. This article is published under the Creative Commons Attribution (CC BY 4.0) license. Anyone may reproduce, distribute, translate and create derivative works of this article (for both commercial and non-commercial purposes), subject to full attribution to the original publication and authors. The full terms of this license may be seen at http:// creativecommons.org/licences/by/4.0/legalcode

Received 14 March 2019

Revised 25 September 2019

21 January 2020

13 March 2020

Accepted 26 March 2020 
costs and still gain more value (Kaplan and Porter, 2011). Thus, health care logistics has become an important development area for health-care organizations and a constantly growing field of research (Volland et al., 2017). However, there is still a gap in the current understanding of how the actors develop health care logistics services together to reach the goals of cost efficiency and better care.

Most of the health care logistics research focuses on care processes and patient flows (de Vries and Huijsman, 2011) while research on supporting material flows has been quite limited (Olsson et al., 2014; Vissers and Beech, 2005: 26). The main difference between these research areas can be illustrated by using the terms patient logistics and non-patient logistics (Bamford et al., 2009). The division has been attributed to the complex nature of health-care supply chains and logistics in health services merely having a supporting role (Beier, 1995; Abdulsalam et al., 2015; Jarrett, 1998). However, the importance of material flows in health-care systems is gradually becoming recognized and the potential improvements that can be accomplished are gaining increasing attention (Landry and Philippe, 2004; Kumar et al., 2008; Kotavaara et al., 2017). In this study, our focus is on the hospital's material logistics, an under-researched area that aids in developing health care logistics in a more cost-efficient and value-creating direction.

In practice, health-care systems have various material flows in different logistics support services such as material supply, a pharmacy service, instrument maintenance, food supply, an assistive device service and a laundry service. These services support actual health services by providing the needed supplies to the care chains. Material flows inside hospitals are taken care of by logistics unit personnel and nursing staff. These occupational roles are naturally far from each other and divergent objectives, such as the lack of a common language, hinder collaboration between them (Kekkonen et al., 2018). However, as our empirical study indicates, a growing physical distance can also have a positive impact on the relationship. This led us to look at the interaction between the two parties and, more specifically, to explore the value co-creation dynamics between them.

This paper adopts the service logic (SL) view on exploring health care logistics as it offers a management-level perspective on value co-creation (Grönroos, 2008; Grönroos and Voima, 2013). Accordingly, in this study value is defined as value in use, created by the user (or emerging for the user) during the usage of resources and processes (Grönroos, 2008). The SL view states that value co-creation is based on interactions between the customer and service provider and that the value generation process comprises three value spheres: a provider's sphere, a joint sphere and a customer's sphere (Grönroos and Gummerus, 2014). If a service provider manages to engage with the customer's value creation process in the joint sphere, opportunities for value co-creation exist. Ideally, they develop a merged, dialogical, coordinated process where both parties operate within each other's processes. The existence of this joint sphere, with its direct interactions, provides a platform for value co-creation. However, although this view has received a lot of theoretical support (Wetter-Edman et al., 2014; Sorrentino et al., 2016), we found that empirical research on the spheres and their development and dynamics is very scarce. Therefore, more research is needed on how the joint sphere is formed, maintained and developed (i.e. on how value cocreation can be facilitated and enhanced in practice).

The purpose of the study is to explore the dynamics of value co-creation in the context of health care logistics by focusing on the change in the value co-creation. This is done by identifying and describing the development of interaction between the logistics service provider and hospital organization (i.e. the customer), concentrating on the conditions, activities, critical events and experiences of the parties involved before and after the change in the logistics arrangements. Our study thus illustrates how a value creation sphere evolves over time as a result of changes in the interaction between the service provider and the customer. Theoretically, this study contributes to the extant research on value co-creation by providing a new understanding of the dynamics of value co-creation and, more specifically, about the development of value creation spheres in the rarely studied context of health-care material logistics. Managerially, the study provides implications for how to develop health-care material logistics to provide more value for both the service providers and their customers.

This study is organized as follows. In Section 2, health-care material logistics and the concepts of value creation and cocreation are discussed to create a comprehensive theoretical understanding of the research phenomenon. Thereafter, the methodology used in this study is introduced in Section 3. Section 4 defines the empirical setting and presents the case analysis that is then summarized in Section 5. Finally, the conclusions of the study, including the theoretical, managerial and social implications, as well as the limitations and future research suggestions, are presented.

\section{Value co-creation in health-care material logistics}

2.1 Health-care material logistics arrangements

Health-care material logistics focuses on ensuring the needed items are available to the nurse, surgeon, clinician, or caregiver in the right place, at the right time and in sufficient quality and on the quantity of superior health outcomes for patients within the health system (Ledlow et al., 2017). The flow of goods can be divided into external and internal supply chains (Landry and Philippe, 2004). The external supply chains begin from the raw material resources to manufacturers and suppliers through wholesalers and logistics service providers who transport the goods to the hospitals (Volland et al., 2017). In hospitals the internal supply chain distributes the items to where they are needed (Moons et al., 2019). Typically the actor who is to receive goods into internal supply chain is the hospital's central warehouse, which is traditionally located inside a hospital to ensure fast supplies and availability (Rivard-Royer et al., 2002). Furthermore, a central warehouse may also be closely connected to other support services, such as a pharmacy service (Volland et al., 2017), food supply, instrument maintenance, a laundry service and an assistive device service (Pohjosenperä et al., 2018). The central warehouse regularly delivers to the point-of-use inventories that are typically located close to patient care locations (Bijvank and Vis, 2012). Apart from this "traditional method," two other goods distribution models are typically applied in practice: semi-direct delivery, where the suppliers skip the central warehouse and deliver directly to the 
point-of-use location and direct delivery, where the supplier takes responsibility for reacting to patient demand and refilling supplies at the point-of-use locations (Aptel and Pourjalali, 2001).

According to Kekkonen et al. (2018), health care logistics services engage both logistics service personnel (drivers, shelving service personnel, warehouse personnel) and nursing staff. However, the task allocation is variable, and challenges arise from the lack of a joint interface between the two personnel groups. In other words, nursing staff and logistic unit personnel do not naturally encounter each other in everyday work. The situation calls for resilience in adapting the tasks of the logistics unit and the nursing staff to achieve positive outcomes.

\subsection{Value dimensions of logistics services}

As suggested by previous research (Yazdanparast et al., 2010), customer focus and the importance of customer understanding are critical parts of value co-creation and widely acknowledged, but much less practiced, in logistics services. Key challenges for logistics managers can be, for example, identifying the appropriate services desired by the customers, delivering the services in a cost-efficient manner, and continually and proactively updating the services. Traditionally, there have been many different ways to conceptualize the value of the logistics services. It has been defined, for example, as an ability to deliver the right product, in the right amount, to the right place, at the right time, for the right customer, in the right condition and at the right price (Shapiro and Heskett, 1985). On the other hand, logistics has been suggested to create value for the customer through efficiency, effectiveness and relevancy (Langley and Holcomb, 1992).

Specifically in the health-care context, the value related to logistics services has been seen to be centered around reliability, resilience, ease of access and comprehensiveness, factors that play significant roles in both employee well-being and productivity (Kekkonen et al., 2018). Moreover, fluent cooperation results in care personnel having less stress and more time for patient work - as well as increased reliability and security - these all increase the operational efficiency of healthcare organizations (Pohjosenperä et al., 2018). These are important aspects to understand in developing logistics services further. However, we agree with studies of Corsaro and Snehota (2010) and Lehtimäki et al. (2018) that found that these kinds of categorizations only offer a partial and often too rational and organized, view of the value. Therefore, instead of focusing on identifying and defining measurable service attributes, a more extensive customer-oriented approach and understanding of value co-creation is needed.

\subsection{Value co-creation in health care logistics}

During recent decades, service marketing research has focused on value co-creation and customer orientation (Vargo and Lusch, 2004; Grönroos, 2011; Heinonen and Strandvik, 2015). In general, co-creation has been defined as the joint, collaborative, concurrent, peer-like process of producing new value, both materially and symbolically (Galvagno and Dalli, 2014). When discussing value co-creation within collaborative B-to-B relationships, it is suggested that both parties aim at mutual value creation and share the outcomes received in this way (Gummerus, 2013).

Existing discussions on value co-creation emphasize the characteristics of the wider service ecosystem (i.e. servicedominant logic: Vargo and Lusch, 2011; Vargo, 2008) or the role of the customer (i.e. customer-dominant logic: Heinonen et al., 2010; Heinonen and Strandvik, 2015). In these studies, the appropriate framework for analyzing value co-creation is the service ecosystem or the customer and not interaction in dyadic relationships. In the SL view introduced by Grönroos $(2008,2011)$, value is considered as value in use, created by the user (or emerging for the user) during the usage of resources and processes. The value of a service is not formed by one particular item or service but by any supporting interactions between the service provider and the customer (Gröonroos, 2011). Thus, this view emphasizes that value co-creation is based on interactions. In addition, SL suggests that value is co-created in some circumstances and not in others. According to Grönroos and Voima (2013), different forms of value cocreation take place in three spheres (the customer's sphere, joint sphere, and provider's sphere) (see Figure 1). In the customer sphere, value is created by customers and other actors in their environment. The service provider then has no direct connection to the customer sphere; but in the joint sphere, interaction between customer and provider is enabled. In the provider sphere, the service provider compiles resources to facilitate the customer's value creation in the other spheres. From a value co-creation perspective, the joint sphere is important because here the service provider's and customer's processes may possibly merge and the actors may influence each other's processes and thus also influence the value formation process (Grönroos et al., 2015).

In this study, we are interested in how these spheres appear and develop in the specific context of health-care material logistics where the relationship between the service provider and its customer can be rather complicated (Kekkonen et al., 2018). In relation to this, Holmqvist et al. (2015) have analyzed the role of psychological distance in the different value spheres. They noted that psychological distance (i.e. the customer's sense of closeness to the service interaction) can aid in understanding the different ways in which the intricacies of an interaction might influence the way in which value is cocreated. As a result, they found that reducing psychological distance increases the willingness of service providers and customers to interact with each other during value co-creation processes in the joint value sphere. This is important since the outcome of the service ultimately depends on a close interaction in the joint value sphere (Grönroos and Voima,

Figure 1 Value creation spheres

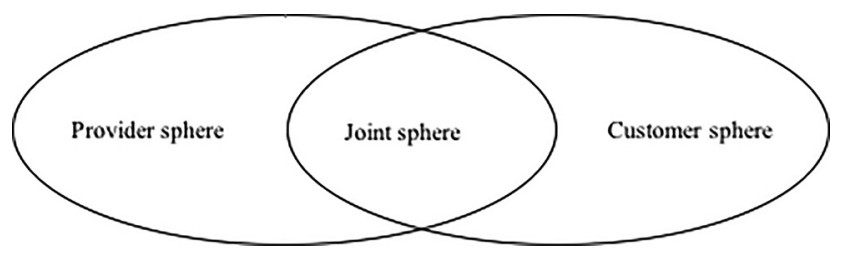

Source: Grönroos and Voima (2013) 
2013). However, it is still unclear why and how increased physical distance in particular influences the interaction between the parties in the joint value creation sphere. Therefore, with the above pre-understanding, we next continue with an empirical study in order to find out whether there is any value co-creation between the logistics service provider and its customer and, if so, what kind of forms it takes and, most importantly, how it develops over time to result in dynamics in the value creation spheres.

\section{Research design}

\subsection{Field of the study}

This research is based on a case study and aims to describe the features, processes and context of a phenomenon (Yin, 2009). A qualitative case strategy is reasonable when issues are complex and where alternating between the empirical field and different theoretical frameworks can be useful for generating additional insights (Orton, 1997; Yin, 2009). According to Baxter and Jack (2008), a qualitative case study is well-suited to exploring complex phenomena within its context. Furthermore, the case study method is used to create novel and creative insights to contribute to the existing theory and practices in B-to-B marketing (Johnston et al., 1999) and logistics supply chain management (Hilmola, 2018).

The empirical case examines a public university hospital in Finland. The hospital provides specialized and demanding health-care services for 750,000 patients in its responsibility area, geographically covering about a half of the country. The largest cost center of the hospital is the surgical ward that conducts 10,000 operations annually. Thus, the material flows, and both the amount and complexity of operations are significant. The in-house logistics unit is a part of the hospital organization and operates the material flows from 600 suppliers to 1900 points of use inside and outside the hospital. Only a limited number of single transport routes are outsourced to external logistics services providers (LSP). This study focuses on the big change in logistics arrangements that occurred in 2017 when the warehouse facilities moved to a different location outside the hospital campus.

\subsection{Data collection}

Data collection combines a variety of information sources including interviews and focus group discussions. Semistructured interviews were used as they enable the researcher to dig into information and ask for clarification and to gain respondents' opinions and perceptions regarding complex and sometimes sensitive issues (Louise Barriball and While, 1994). Focus groups were used as they are useful in identifying important qualifiers or contingencies that may be associated with an answer to a structured question. Furthermore, focus groups offer an opportunity for feedback from and responding to the comments of others (Stewart and Shamdasani, 2014). The data is detailed in Table 1.

In addition to the interviews and focus groups, the empirical data also relies on multiple other sources. Firstly, background knowledge of the organizations was compiled in making a pre-study of the university hospital logistics (in 2012) and in, discussions with the hospitals and the logistics unit (20132014). This period consisted of fieldwork that gave an understanding of the conditions in the hospital. Also, several interviews included tours of the logistics and health-care facilities. The tours gave an overview of the facilities in which the logistics services meet the end user. At that time the topic of this research was discussed multiple times during a multidisciplinary research project that ran 2014-2016. In this phase, a group discussion was arranged to simulate a value cocreation process between a health-care customer unit and an LSP organization to ideate and open up views to new health care logistics service possibilities based on both the logistics services used in other industries and first-hand experience of nursing work. Finally, after the warehouse moved to the new location, interviews were arranged (between late 2017 and early 2018, and, finally, in early 2019) to update the information regarding logistics and value co-creation procedures.

\subsection{Data analysis}

The nature of this case study is abductive systematic combining. The research process is, thus, a nonlinear, pathdependent process that combines efforts to match reality and theory. Therefore, the case analysis, empirical fieldwork and theoretical framework evolved simultaneously throughout the research process. Various research activities and going back and forth between theory and empirical observations expand the understanding of both the theory and empirical phenomena (Dubois and Gadde, 2002). Thus, the findings can be abductively inferred from the data with simultaneous matching with and reflecting against the proposed theoretical underpinnings (Kovács and Spens, 2005).

The hospital's material supply chain descriptions from before and after the change were drawn and redrawn multiple times during the research process. The descriptions and material flow figures were first sketched out with the understanding gained from the pre-study, then updated on the basis of the interview data and compared to the literature resulting from ongoing research Finally, the descriptions were validated through a review round with the interviewees. Data analysis before the change also included reading through the transcriptions of the interview and focus group data multiple times, coding and organizing them manually under conceptual themes derived from value co-creation literature (actor roles, value expectations and value creation spheres).

The moving of the warehouse came as surprise for the researchers. The new situation gave a fresh view on the previous interview and focus group data that was, again, manually coded and rearranged by themes that could be analyzed through value co-creation literature illuminating the lacking joint value sphere before the change. In detail, the coded transcriptions were arranged into groups and brought together under the themes by both rephrasing the content and using quotes from the interviews. The last interviews focused on the change and the situation after that. This, together with value co-creation literature, gave the researchers an understanding of the visible changes in value co-creation through discords, events for co-creation and changes in value creation spheres.

\section{Empirical analysis}

This section first presents an overview of the material supply operated by the logistics unit in the case hospital as it was before 
Table 1 Data collection

\begin{tabular}{|c|c|c|c|c|}
\hline Organization & Position(s) & Type & Date & length \\
\hline Surgery ward & Staff Nurse and Nurse, Anesthesiology & Semi-structured interview & 8.1 .2015 & $1 \mathrm{~h} 7 \mathrm{~min}$ \\
\hline Surgery ward & Staff Nurse & Semi-structured interview & 13.1.2015 & $46 \min$ \\
\hline Surgery ward and the LSP & Staff Nurse (Anesthesiology) and Area Manager & Focus group & 4.2 .2015 & $1 \mathrm{~h} 58 \mathrm{~min}$ \\
\hline Regional hospital, city procurement & Development Manager, Procurement Expert & Focus group & 27.5.2015 & $17 \mathrm{~min}$ \\
\hline Logistics unit, consulting company & Procurement Manager, CEO & Focus group & 27.5.2015 & $23 \min$ \\
\hline $\begin{array}{l}\text { The university and regional } \\
\text { hospitals, the municipalities, LSP, } \\
\text { other service providers }\end{array}$ & $\begin{array}{l}\text { Head of Procurement, Area Manager, } \\
\text { Development Manager, CEO, Material and } \\
\text { Logistics Manager, Program Leader, } \\
\text { Warehouse Manager, Apothecary }\end{array}$ & Seminar group discussions & 18.2.2016 & $2 \mathrm{~h} 51 \mathrm{~min}$ \\
\hline Logistics unit & Head of Procurement & Semi-structured interview & 1.4 .2016 & $33 \mathrm{~min}$ \\
\hline LSP & Area Manager & Semi-structured interview & 13.4 .2016 & $56 \min$ \\
\hline \multicolumn{5}{|c|}{ The warehouse moved to the new location in spring 2017} \\
\hline LSP & Area Manager & Semi-structured interview & 7.12 .2017 & $87 \mathrm{~min}$ \\
\hline Logistics unit & Logistics Manager and Warehouse Manager & Semi-structured interview & 7.2 .2018 & $1 \mathrm{~h} 11 \mathrm{~min}$ \\
\hline Logistics unit & Head of Procurement & Semi-structured interview & 7.2.2018 & $40 \mathrm{~min}$ \\
\hline Surgery ward & Staff Nurse (Anesthesiology) & Semi-structured interview & 12.2 .2018 & $44 \min$ \\
\hline Logistics unit & Transport Manager & Semi-structured interview & 18.2.2019 & $1 \mathrm{~h} 18 \mathrm{~min}$ \\
\hline Logistics unit & Warehouse Manager & Semi-structured interview & 22.2.2019 & $1 \mathrm{~h} 2 \mathrm{~min}$ \\
\hline
\end{tabular}

the reform in 2017 and later, after the changes in the processes. Then, the actor roles of value co-creation, the value expectations, and the value creation spheres before the change are analyzed. The situation after the reform and its impact on value co-creation are analyzed in Sections 4.4, 4.5, 4.6 and 4.7.

\subsection{Description and the evolution of the empirical setting}

The material flows of the case hospital contain a broad variety of items, such as medical supplies, dental care supplies, laboratory supplies, rehabilitation devices, sanitizers, tissues, disposables, office supplies, grid supplies, furniture and machines. Hence, this paper outlines many logistics services that require their own supply chains and facilities (such as those of food supply and a hospital pharmacy) and services with closed loop supply chains where the same material circulates between points of use and maintenance facilities (e.g. the laundry service, instrument maintenance and the assistive device service).

\subsubsection{Material supply chain in the hospital before the change}

In the case hospital, most of the shipments arrived from suppliers and wholesalers to the goods receiving terminal located in the hospital building (see Figure 2). The total volume of goods in one day was, on average, $66 \mathrm{~m}^{3}$ or 55 EURpallets. Thirty per cent of the received goods were directly moved towards the points of use (clinics and departments) while $50 \%$ of the goods were moved to a central warehouse (intermediate storage); in the warehouse goods were unpacked, shelved and picked out by need and delivered to the points of use. The remaining $20 \%$ of the goods went to customers outside the hospital campus.

The logistics unit has broadened their service by offering a shelving service for the points of use. This service is related to the vendor managed inventory offered by the logistics unit. In the points of use, there are storage rooms, shelves and closets (the automated medication dispensing system, Pyxis) that are inspected and later filled by a person from the warehouse. The shelving service is very much liked and demanded at the points of use as it enables nursing staff to focus more on direct patient work instead of logistics tasks, such as ordering, unpacking and shelving.

The warehouse was located in the hospital building, which made it possible for nursing staff to get missing goods from the warehouse without having to "officially" order them and wait for the items to arrive. That was considered a good "backup" procedure, for example, it can be used during surgeries if something urgent or unexpected occurs. From the logistics unit's point of view, this so-called shopping was justified but, in some cases, the items are picked by the nurses without any urgent need for some other reason.

\subsubsection{Material processes after the change}

The case hospital is currently under major renovation as many parts will be completely rebuilt by the year 2030. In the first phase of the renewal process, the warehouse facilities were demolished to make space for new constructions. Thus, the warehouse is now relocated to an industrial building (later in the text, the New Warehouse), some $10 \mathrm{~km}$ away from the hospital. This has changed the material processes (see Figure 3) and warehouse organization, as well as the offered logistics services.

Now the goods from suppliers are received at the New Warehouse, where also some of the goods are unpacked and stored for later order picking. The rest of the hospital goods and the picked trolleys are transported to the hospital by two trucks that circulate between the hospital and the warehouse multiple times per day. In the hospital the goods are unloaded from the trucks to a terminal inside the hospital, from where the goods are delivered to their points of use, such as storage rooms and cabinets in the clinics. 
Figure 2 Material flow of the case hospital before the change

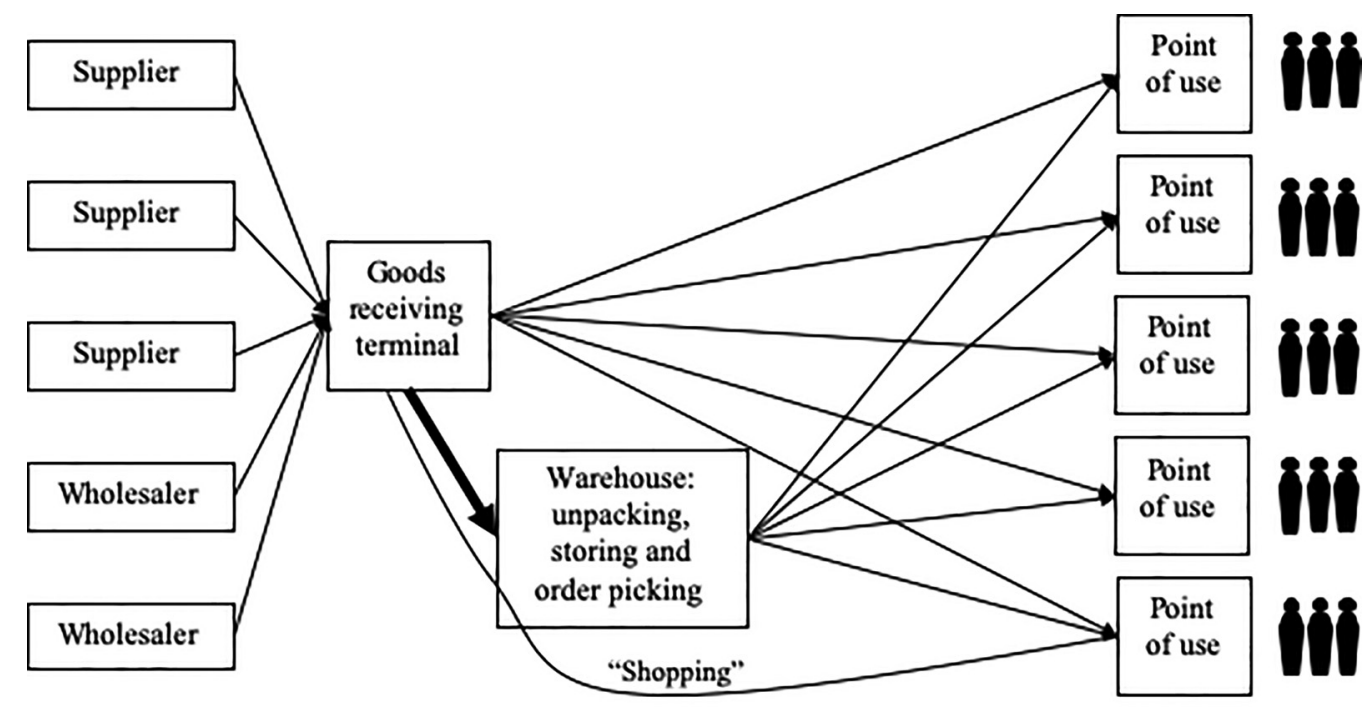

Figure 3 Material flow of the case hospital after the change

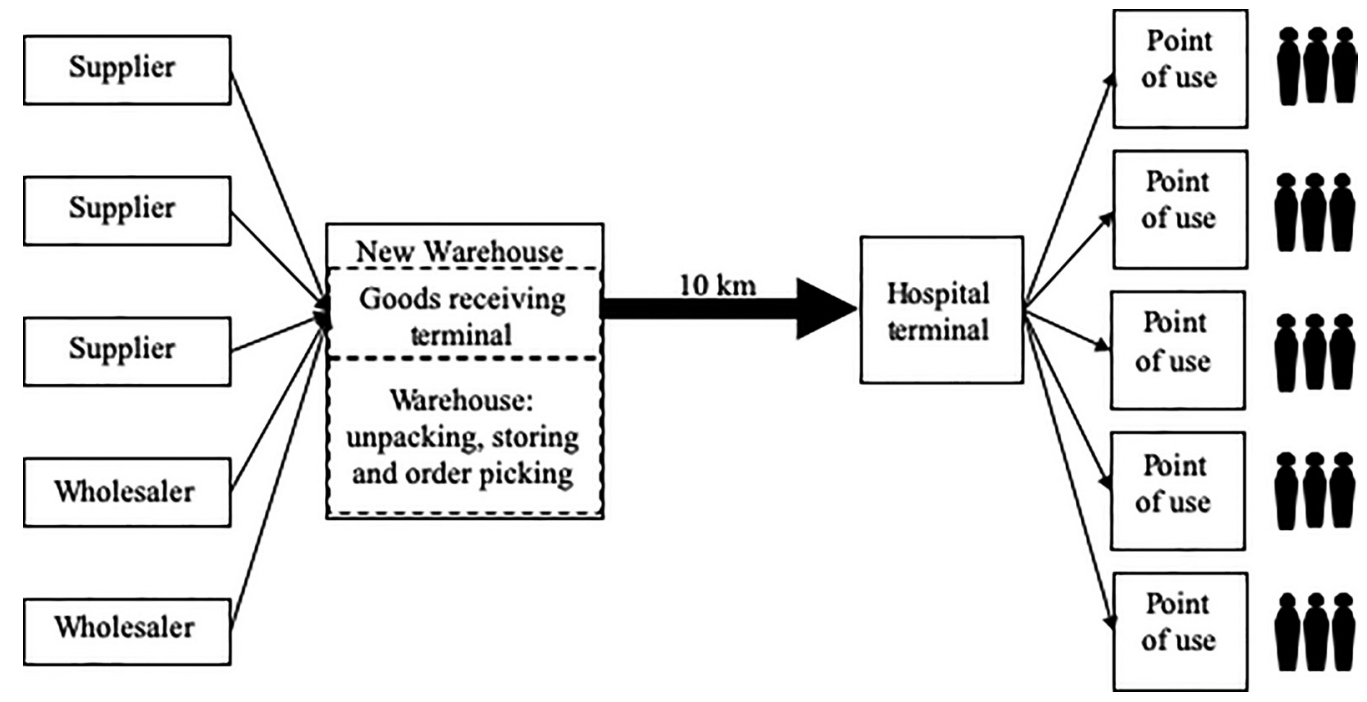

With this pre-understanding of the empirical setting, we next illustrate the development of value co-creation with the case where a change in the logistics arrangements between the customer (i.e. the hospital surgery ward) and the logistics unit had a major influence on value co-creation between the parties.

\subsection{Actor roles in value co-creation}

Concerning the different actor roles, it is important to also consider all the participants of value co-creation at a more specific level. Thus, the whole chain of actors and their specific roles need to be understood. The interviewees pointed out that there are multiple actors - such as those involved in transportation, procurement, the warehouse and different care units - inside the hospital who are involved in creating and perceiving value:
The whole chain that begins with the supplier, then the transport company that brings the goods, and then the central warehouse that receives the goods at the hospital. Our internal logistics bring the goods into the ward and then in the ward the nurse [...] it is the whole chain. Everything must function perfectly. (Staff Nurse 2)

The logistics unit seems to be aware of its role in being expected to create safety and trustworthiness. In other words, people know they will hear complaints if there are any faults in the service. Actually the "no complaints" situation is considered to indicate success in meeting customer expectations:

When nobody has seen us, nor heard us, and the goods are delivered, then we have succeeded perfectly [...] no feedback is the best positive feedback for us. (Transport Manager)

Hence, the logistics unit does not ask for feedback about its work and does not actively strive to enhance events for value cocreation. This attitude seems to cause inefficiencies in 
developing the service and structuring the service organization and procedures "around" the expected value of the services. The following comment describes the logistics service's challenge in defining their role in health-care organization:

It's not an easy task. It's easy on paper, but [...] The thing is how you do it and measure it. And then it needs a good case. Then you can prove how much it's worth [...] If you could prove that by wisely including some new logistics service concept you could take one day off the care chain. (the CEO of a consulting company)

This can be especially problematic from the value co-creation perspective. If there is no genuine communication between the logistics unit and the customer in the current situation and if the former does not even want to engage in discussions (e.g. in terms of feedback), then the interaction between the parties would seem to be quite remote.

Overall, the health care logistics services have multiple actors affecting and perceiving value. The patient's view is central, but the patient is not necessarily the one who creates or perceives the value. Especially in the surgery ward, the nursing staff use the supplied items and, hence, the logistics service. The focus of this study is on the value creation spheres between the organizational customer (i.e. the surgery ward) and, more specifically, the nursing staff directly using the logistics services and the logistics unit since these are the key actors who actively interact with each other.

\subsection{Value expectations}

Considering the expectations for logistics value in health care, the interviewees highlight the functionality of the service. The supplied items are crucial for a successful operation in many operations, and therefore the supply should be trustworthy. In addition, safety and reliability are seen as critically important factors. One of the interviewees summarized the logistics service value as follows:

The value is that we get the patient treated. It is our main thing. Everyone must have the right screw or prosthesis or plate or whatever; they must be in the right places and then there is good care. The item is first shipped by a transport company, then we get it into our central warehouse and delivered here, and then we put it into the right place. So good care is guaranteed in this respect. (Staff Nurse 2)

The central part of logistics value and co-creation is the task allocation that helps nursing staff to concentrate on nursing work instead of logistics tasks. However, the interviews indicate that this is not always understood or even wanted. For example, in some cases nursing staff want to do some logistics work by themselves to ensure safety and sometimes for some other reason:

Here we had cases where the nurse went - in the middle of and operation to the central warehouse to pick up some needed item. Then, the critical time the patient spends in the operating theatre gets longer. That time can be shortened by redesigning logistics services. This is an example of the benefits of logistics; then the nurses can concentrate on what they are best at (i.e., taking care of the patient). (an Area Manager of the LSP)

In addition, the processes behind the logistics service seem to affect at least the image of logistics service trustworthiness and thus, in turn, the value:

For example, when the item arrives to the hospital, you need to trust the transport and shelving services. If a link in the chain fails, the whole chain malfunctions. (Nurse)

However, it is stated that if the service can be trusted, the processes behind the service becomes less important:
I would say that as the items arrive, the color of the truck doesn't matter it's important that the item arrives. The security of supply must be unconditional. The process should be observed every now and then to see if there is any room for improvements. (Staff Nurse)

The expectations for value seem to be primarily associated with patient care and expectations, and also with the nursing staff's safety, reliability and well-being. However, these outcomes are considered stronger if the nursing staff is aware of the backoffice operation. Therefore, moving the warehouse is considered to have weakened the trustworthiness of the logistics service as the nursing staff have fewer opportunities to affect and monitor the back-office processes.

\subsection{Lacking a joint value sphere before the change}

Before the change, the logistics unit and the customer did not develop the service together. Also, other actors, such as LSPs, had an interest in getting to offer and co-create services with the hospital and the care units, but they faced challenges in getting to talk with the right people:

We rarely get to talk with these people in the care units. [...] we don't get to talk with the nursing staff because it must be the boss of the boss, on a certain level, who is directed by money and then measures the effectiveness of the care by how much more time for care tasks we get with these results and how much it saves in expenses. (an Area Manager of an LSP)

In relation to the lack of communication with the right people, different actors seem to focus on different things that they see as important. For example, transport costs or delivery time seem to be important to some whereas others do not see them as relevant aspects at all. This asymmetry in the perspectives of the actors also hinders value co-creation between the parties:

Hospital logistics is measured like a logistics unit in any other organization: by the price of order picking, the delivery time, etc. It's not measured if an item reaches care operation at the right time or does it make care chain faster. (the CEO of a consulting company)

One big challenge is that there are so many different actors at different levels of organizations involved, and they all concentrate on different things. This means that the big picture becomes blurred as everyone is focusing on their own priorities. For example, LSPs do not seem to have access to co-creation as they only have separate conversations with certain persons in the hospital organization:

Nobody develops the entity; every point of use separately discusses with the warehouse manager, and then there is the procurement unit in the middleso nobody sees the entity. (an Area Manager of an LSP)

The hospital organization wants to keep the reins in its own hands. Something is considered to be lost if larger entities are outsourced to LSPs. Thus, from the LSP's point of view, the hospital organization may seem self-sufficient and managing small details instead of leading the entity. From the value cocreation perspective, this can be seen to be a problem since severe asymmetries in information sharing cause interruptions in interaction.

Another challenge is the lack of the certain "service mindset" that would highlight value co-creation. Instead, the hospital and its logistics unit were criticized for focusing on their own organization and thus neglecting co-creation opportunities with LSPs:

Public organizations put something out to tender, which they do well. And there are many kinds of offers, and it's usually the price that matters. Usually the transport is included in the price so they don't see the transportation costs, and therefore, these things are not developed. (an Area Manager of an LSP) 
The existing logistics services are not built around value. They are built around the organization, not around customer value, in order to optimize the organization's functioning. (Regional Hospital Development Manager)

Due to the challenges presented above, the actors are lacking a shared view of the needed joint value creation sphere, which results in the absence of co-creation activities between them. Thus, the actors seem to have grown together into a situation where they do not need to develop their business relationship but only avoid mistakes and contact of any kind. Figure 4 illustrates this situation of the two actors in the same hospital organization without a visible joint value creation sphere.

Next, we analyze the changes in value creation after the case hospital moved the central warehouse to another location (the New Warehouse).

\subsection{Visible changes in value co-creation through discords}

During and right after the change, the customer questioned the logistics unit's ability to deliver the needed items correctly. Errors were reported to be caused by the change, a claim that the logistics unit disagrees with:

The distance to the New Warehouse, as an experience or prejudice, is seen by the customer-we are no longer in the same neighborhoods of the hospital area."?. So, there are doubts, even in the smallest cases, that is the logistics unit is able to deliver from the new location. But now we have the time to prove to them that we can accomplish the service from there, and thus win their trust. (Procurement Manager)

The reported errors might be caused by the traditional setting where the logistics services purely follow the needs of the health-care customer organization. In elective surgeries there is an operation schedule that drives logistics service processes. However, this schedule might change (e.g. due to emergency situations). The logistics service processes are not considered when planning these operations. As an example, there were three elective surgeries scheduled with the need for certain special prosthesis (a month beforehand) that were to be operated within a two-day period. Due to the rare need for the item, the inventory level was set low. Thus, the logistics unit could not deliver one of the prosthesis in time. This resulted in the cancellation of one operation with the stated reason of the "failure of the logistics unit because the warehouse moved to another location," which was not the case.

Our side cannot affect the operation schedule [...] if there were one person who would understand both sides, who would check and say "Hey, there are no XL prosthesis because those are only used five times a year, so there cannot be three operations within two days [...] However, these cases teach us. Through these discords, we get in touch with the root cause and, in that sense, the co-operation can increase. (Transport Manager)

The moving of the logistics unit seems to be a good excuse for errors in the operations. On the other hand, the change has made the challenging issues visible, which has led to increased

Figure 4 Lack of a joint value creation sphere between the logistics unit and customer organization before the change.

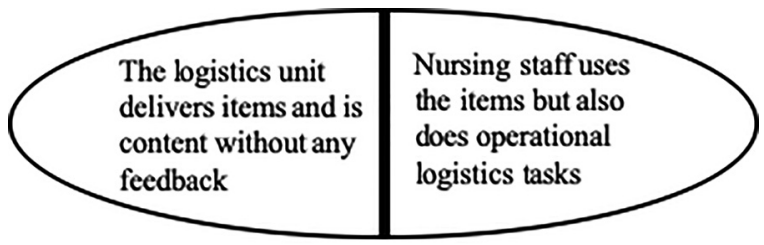

communication and interaction between the parties (i.e. the cocreation of value). The earlier situation (when the warehouse was located close to the customers) allowed deviation from normal processes, and thus actions that could not be measured:

Through these challenges we have got the possibility to discuss with the customers more. So, therefore, I see that the change has in fact been good [...] The change made this fact-based discussion possible. (Procurement Manager)

Due to the change, the ad hoc attitude seems to be replaced by more systematic collaboration and interaction, which in this case means readjusting the inventory levels of the relevant items, together with the involvement of both the logistics unit and the customer. This indicates that value co-creation between the parties has significantly improved because of the change.

\subsection{Events for co-creation}

After the change, the logistics unit and the customer have arranged meetings to find the root cause and solutions for the bottlenecks in the processes:

The change is good in the sense that the service requirements became visible. Now we can genuinely begin to enhance the processes together and fit the service level. We don't have a kind of feelings-based discussion like "Why do we have nothing here?" (Procurement Manager)

The representative of the customer organization has experienced an instant growth in joint meetings between the logistics unit and the customer organization:

We had weekly meetings and now they are around monthly. There are members from instrument maintenance, the shelving service, the pharmacy, the logistics unit, the managers and staff nurses of both surgery and anesthetics. [...] We bring up problems from the error diaries and discuss how the issues could be solved. We have actually started to scan the diaries frequently and send them to the warehouse in order for them to tackle the deficits and faults faster. (Staff Nurse)

The joint meetings and the error diaries have resulted in, for example, adjusting the inventory levels of the material closets that are located close to the wards. During the joint meetings, co-creation takes place in more or less unofficial discussions between the nursing staff and the logistics support service personnel. One result of these discussion is the consensus regarding the need to get more education for the logistics personnel in order for them to better understand the items they deliver and thus better respond to the needs:

We now have good verbal contact with the shelving service as we know who visits us - we can just call them, even daily [...] We also unofficially discuss things in the corridor as we see them in the morning when they arrive and at noon as well. If I go by, we always say a word or two. (Staff Nurse)

Another example of co-creation is placing the items into material closets (i.e. designing the planographs) in accordance with the operational entities instead of traditional inventory categories:

At first, they arranged the heaviest items in the lower sections, which is logical, but then they were all messed up. We have guided them to place the items according to operational entities. Now there are big signs indicating where there are masks and so on; it is similar to grocery stores: "Here we have eggs and sugar." (Staff Nurse)

Now the planographs are done together by the nursing staff and the logistics unit. However, the nursing staff would like to take a step even further by arranging the shelves entirely by themselves. However, the logistics unit want to have their say too as it is such a central part of their work to know the planographs and know that the storage rooms are somewhat 
standardized throughout the hospital. Overall, the increased co-creation sphere appears in events such as joint meetings, designing and planning together and in daily discussions.

\subsection{Changes in the joint value creation sphere}

The case organizations had functioned physically close for decades. This analysis illustrates that when the physical distance increased by moving the logistics unit into to another location, logistics processes needed to be changed causing discords that further required more interaction between the parties. This led to a widening of the joint value creation sphere. The discords have made the customer needs recognizable as the inefficiencies and potential risks have become visible. The services are now more manageable. Examples of the activities that are done by the logistics unit, by the customer themselves, and those done together in the joint sphere are illustrated in Table 2.

In renewing the logistics services, the logistics unit has changed its back-office arrangements. This was done by, moving the warehouse into modern and functional facilities, designing the layout of the warehouse, implementing a new enterprise resource planning system, re-adjusting the inventory levels, scheduling the transports and also by buying the transport services needed to facilitate customer value creation. The customer has done its share too, firstly by using the items in patient care but also by monitoring and reporting the errors. Then again, the value co-creation has taken place in direct interactions: joint meetings and daily discussions about arranging the planographs and closets and planning the reception and pick-up areas for non-daily deliveries. Overall, both counterparts see that the services have been improved and that there is more co-creation now than there used to be:

The fact is that there are the errors and discords, and then it is a necessity to cooperate [...] I think that at the moment we are doing more together just by these examples. We begin to understand each other more. (Transport Manager)

Interaction has increased in, let's say, doing things together, planning together, etc. We have aimed to both have the possibility to bring up issues in order to make things better. It's a sort of think tank for what could be done. They know a lot and they serve the whole hospital, but we aim to give them tips regarding what should be in order and which things are the most important. (Staff Nurse)

\section{Summary of the empirical findings}

Now, two years after the change, the logistics services have enhanced. For instance, the storage rooms near the points of use are better organized and their inventory levels are set to meet the needs of the healthcare services. Therefore, there are less errors in logistics service processes and more functional procedures to solve errors if they occur. The processes are mostly routinized, and the frequency of the meetings has already decreased. However, the actors report that the meetings are now easy to arrange when needed as the co-creation routines are well established. In the future, the joint value creation sphere might grow further during upcoming changes as the case hospital is being renewed. For example, the operation rooms will be temporarily moved to another location, which is also a big challenge for the logistics unit. On the other hand, the actors become more used to different kinds of change and how to react to change. Thus, the joint value creation sphere becomes dynamic as it widens and diminishes according to the new changes (Figure 5). Our study illustrates how change (in this case, change in the physical location of the service provider) can create a discord that is actually a catalyst for value co-creation between the parties. In practice this means that discords and changes, such as increased distance, can drive forward co-creation but, as the issues become solved and the processes routinized, the co-creation sphere diminishes. As a result of co-creation, task allocation becomes clearer and the actors can enhance their strengths (i.e. nursing staff can concentrate on nursing work and logistics service can make the material processes more efficient). Moreover, the logistics service provider does not necessarily need to be an in-house operator as the back office gets separated from the visible parts of the service.

The empirical findings suggest that the physically close health-care organization and logistics unit had, over time, settled into a status quo wherein the logistics service was "done as always" and thus lacked proper interaction and collaboration between the parties. The close location allowed the actors to merely react to everyday errors and, thus, no sustained improvements needed to be created. This led to inefficiencies in task allocation, unnecessary searching for items, and also to stress for the nursing personnel. When the warehouse moved to a more distant location, one could no longer "go and pick up" the needed items from the warehouse. Therefore, the material processes, inventories, shelving arrangements, and other service processes had to be replanned and restructured. As a result, the actors started to have a natural need to increasingly interact with each other, in other words, to co-create value in the service interface where both actors are active. The cocreation took place both in the joint meetings and daily routines, for example, in reporting and reacting to errors.

In the starting phase, the naturally distant duties of the nursing staff and the logistics unit staff (Kekkonen et al., 2018) created serious challenges for value co-creation. However, the new situation seems to have clarified the roles as the nursing staff are recognized as the actual customers of the logistics services who are the key actors perceiving the usefulness of (logistics) services and also those who experience the pleasant feelings and emotions that the service might generate in them (Batra and Ahtola, 1991; Komulainen and Saraniemi, 2019).

Table 2 Data collection

\begin{tabular}{lll}
\hline Logistics unit & The joint sphere & Customer \\
\hline Restructuring the warehouse & Joint meetings & Using delivered items \\
Enhancing the operations & Arranging the closets & Monitoring errors in service \\
Scheduling the transports & Designing the planographs & Writing error diaries \\
Buying transport services & Planning the receiving and pick-up areas & \\
& Daily discussions & \\
\hline
\end{tabular}


Figure 5 Dynamics of value creation spheres

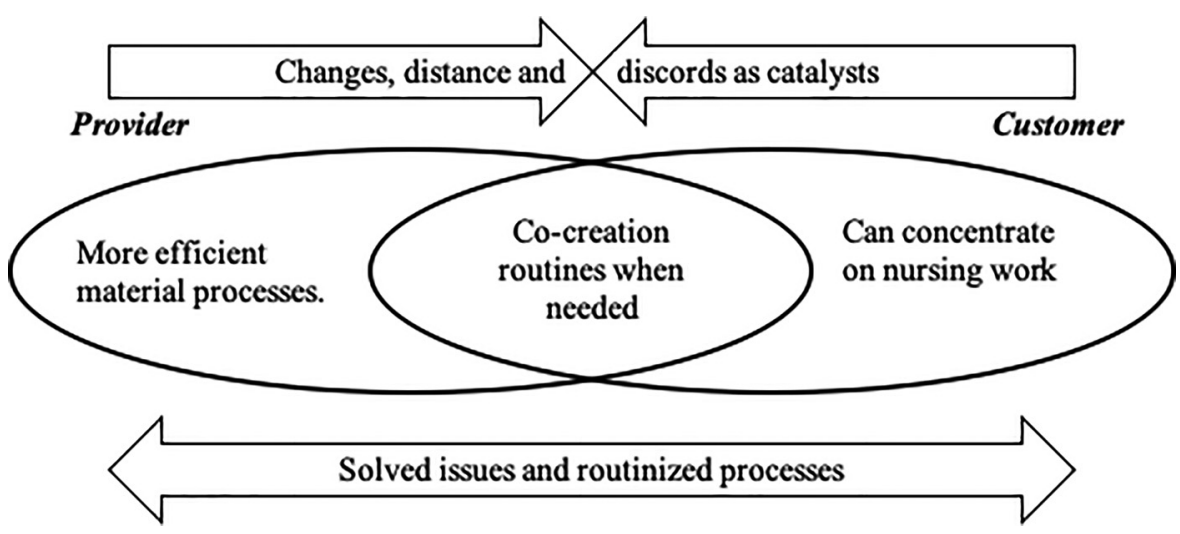

Now the focus can be on how the nursing staff experience the service they are using. With this understanding, the logistics services can be managed to directly support the nursing work and, hence, indirectly support the patient healing process.

\section{Conclusions}

This paper explores the dynamics of value co-creation in the context of health care logistics by focusing on the change in the value creation spheres. The case analysis is presented to identify and describe the development of interaction between the logistics unit (i.e. the provider) and hospital organization (i.e. the customer) by concentrating on the conditions, activities, critical events and experiences of the parties involved before and after the change in logistics arrangements. Our study thus illustrates how value creation spheres evolve over time as a result of changes in the interaction between the service provider and the customer.

Theoretically, this paper contributes to the extant research on value co-creation by providing a new understanding of the dynamics of value co-creation and, more specifically, about the development of value creation spheres in the context of healthcare material logistics. Although value creation spheres have been discussed in numerous conceptual papers (Grönroos and Voima, 2013; Holmqvist et al., 2015; Sorrentino et al., 2016), empirical research on their dynamics is scarce or non-existent. This study illustrates that value creation spheres are not stable but inherently dynamic and changing along with the development of the relationship between the service provider and the customer. At the starting point, the customer's and service provider's spheres were discrete, but when the service process was separated and partly moved to more distant location, the joint value creation sphere became more visible, stronger and more important. This increased the value for both parties through intensified communication, more fruitful meetings, improved formal and informal knowledge sharing, and finally, through having common goals for cooperation. The operations of both actors were enhanced, and they became more satisfied with their relationship with each other. However, the situation is not by any means stable-over time the value creation spheres can again change along with changes in interaction between the parties, for example, as processes get routinized or when new changes and discords again change the situation. It is also important to note that although the value co- creation that takes place in the joint sphere of the customer and service provider is seen as a desirable state, the actors' spheres and value creation within them is also important. Therefore, finding a balance between a sufficient amount of value cocreation and the actors' own value activities is essential and depends on the context and situation in question.

Managerially, this study offers an example of how value cocreation can take place in a changing situation, in this case when the physical distance between two parties increased as a result of a change in logistics arrangements. The co-creation changed the interface between the logistics service personnel and nursing staff, clarifying the task allocation and improving the visible front-office parts of the service. This gave the service provider an opportunity to develop the back-office processes so that they were more efficient. Moreover, this opened up opportunities to reorganize the logistics services, allowing the New Warehouse location and also possibilities for outsourcing certain modules of the service. Overall, changing the location of a warehouse may appear a simple or dramatic change, depending on one's viewpoint, but here it offered an opportunity to enhance value co-creation and increase value for both parties, not to forget the end user.

For societies, understanding value co-creation in health care logistics services helps hospitals and other health service organizations to both develop their processes towards better care for the patients and enhance cost efficiency. Thus, focusing on logistics service arrangements has positive outcomes as health-care systems globally are struggling to manage the future challenges.

As a limitation, this study presents a single case study, focusing on one particular service provider and hospital organization. However, the interviewees were selected carefully to cover the relevant viewpoints adequately. Also, the time perspective, covering the before and after situations, widens the case analysis, bringing out an example of the behavior of the value creation spheres in a changing situation. This paper also suggests research ideas for further study. In the future, it could be interesting to approach value creation spheres from the opposite perspective, namely from the dark side of value cocreation (Chowdhury et al., 2016) or value co-destruction (Echeverri and Skalen, 2011; Plé and Chumpitaz Cáceres, 2010; Plé, 2017), capturing the downside of value co-creation. Exploring actual or potential value co-destruction in individual 
or joint spheres could provide interesting new knowledge related to the dynamics of value creation spheres. In addition, future studies can elaborate on value co-creation in health-care supply chains by, for instance, making structured case studies of several hospitals, studying each engaged party with thoroughly set measures. Regardless, to strengthen the knowledge, more cases about the dynamics of value creation spheres in various contexts are needed.

\section{Acknowledgements}

The authors acknowledge the support from Business Finland, The Council of Oulu Region, European Union Regional Development Fund and other public and private organizations to two research and development projects during which the empirical material for this study was collected. The authors are grateful to the representatives of the health care and logistics service organizations for their valuable contribution during these two projects. The authors also thank our colleagues and the anonymous reviewers of the journal for their comments that have helped to improve this paper.

\section{References}

Abdulsalam, Y., Gopalakrishnan, M., Maltz, A. and Schneller, E. (2015), "Health care matters: supply chains in and of the health sector", Fournal of Business Logistics, Vol. 36 No. 4, pp. 335-339.

Ageron, B., Benzidia, S. and Bourlakis, M. (2018), "Health care logistics and supply chain-issues and future challenges", Supply Chain Forum: An International fournal, Vol. 19 No. 1, pp. 1-3.

Aptel, O. and Pourjalali, H. (2001), "Improving activities and decreasing costs of logistics in hospitals: a comparison of US and French hospitals", The International fournal of Accounting, Vol. 36 No. 1, pp. 65-90.

Bamford, D., Thornton, H. and Bamford, J. (2009), "Health care logistics redesign", Or Insight, Vol. 22 No. 3, pp. 140-152.

Batra, R. and Ahtola, O.T. (1991), "Measuring the hedonic and utilitarian sources of consumer attitudes", Marketing Letters, Vol. 2 No. 2, pp. 159-170.

Baxter, P. and Jack, S. (2008), "Qualitative case study methodology: study design and implementation for novice researchers", Qualitative Report, Vol. 13 No. 4, pp. 544-559.

Beier, F.J. (1995), "The management of the supply chain for hospital pharmacies: a focus on inventory management practices", fournal of Business Logistics, Vol. 16 No. 2, p. 153.

Bijvank, M. and Vis, I.F. (2012), "Inventory control for pointof-use locations in hospitals", fournal of the Operational Research Society, Vol. 63 No. 4, pp. 497-510.

Chowdhury, I.N., Gruber, T. and Zolkiewski, J. (2016), "Every cloud has a silver lining - exploring the dark side of value co-creation in B2B service networks", Industrial Marketing Management, Vol. 55, pp. 97-109.

Corsaro, D. and Snehota, I. (2010), "Searching for relationship value in business markets: are we missing something?", Industrial Marketing Management, Vol. 39 No. 6, pp. 986-995. de Vries, J. and Huijsman, R. (2011), "Supply chain management in health services: an overview," supply chain management", Supply Chain Management: An International fournal, Vol. 16 No. 3, pp. 159-165.

Dubois, A. and Gadde, L.E. (2002), "Systematic combining: an abductive approach to case research", fournal of Business Research, Vol. 55 No. 5, pp. 553-560.

Echeverri, P. and Skalen, P. (2011), "Co-creation and codestruction: a practice-theory based study of interactive value formation", Marketing Theory, Vol. 11 No. 3, pp. 351-373.

Galvagno, M. and Dalli, D. (2014), "Theory of value cocreation: a systematic literature review", Managing Service Quality: An International fournal, Vol. 24 No. 6, pp. 643-683.

Grönroos, C. (2008), "Service logic revisited: who creates value? And who co-creates?", European Business Review, Vol. 20 No. 4, pp. 298-314.

Grönroos, C. (2011), "Value co-creation in service logic: a critical analysis", Marketing Theory, Vol. 11 No. 3, pp. 279-301.

Grönroos, C. and Gummerus, J. (2014), "The service revolution and its marketing implications: service logic vs service-dominant logic", Managing Service Quality: An International fournal, Vol. 24 No. 3, pp. 206-229.

Grönroos, C. and Voima, P. (2013), "Critical service logic: making sense of value creation and co-creation", fournal of the Academy of Marketing Science, Vol. 41 No. 2, pp. 133-150.

Grönroos, C., Heinonen, K. and Strandvik, T. (2015), "Value co-creation: critical reflections", in Gummerus, J. and Von Koskull, C. (Eds), The Nordic School-Service Marketing and Management for the Future, CERS, Hanken School of Economics, Helsinki, pp. 69-82.

Gummerus, J. (2013), "Value creation processes and value outcomes in marketing theory: strangers or siblings?", Marketing Theory, Vol. 13 No. 1, pp. 19-46.

Heinonen, K. and Strandvik, T. (2015), "Customer-dominant logic: foundations and implications", Fournal of Services Marketing, Vol. 29 Nos 6/7, pp. 472-484.

Heinonen, K., Strandvik, T., Mickelsson, K.J., Edvardsson, B., Sundström, E. and Andersson, P. (2010), "A customerdominant logic of service", fournal of Service Management, Vol. 21 No. 4, pp. 531-548.

Hilmola, O.P. (2018), "Supply chain cases", Leading Authors, Research Themes and Future Direction, Springer, Cham, Switzerland.

Holmqvist, J., Guest, D. and Grönroos, C. (2015), "The role of psychological distance in value creation", Management Decision, Vol. 53 No. 7, pp. 1430-1451.

Jarrett, G.P. (1998), "Logistics in the health care industry", International Fournal of Physical Distribution and Logistics Management, Vol. 28 Nos 9/10, pp. 741-772.

Johnston, W.J., Leach, M.P. and Liu, A.H. (1999), "Theory testing using case studies in business-to-business research", Industrial Marketing Management, Vol. 28 No. 3, pp. 201-213.

Kaplan, R.S. and Porter, M.E. (2011), "How to solve the cost crisis in health care", Harvard Business Review, Vol. 89 No. 9, pp. 46-52.

Kekkonen, P., Pohjosenperä, T., Kantola, H. and Väyrynen, S. (2018), "Rational and participative task allocation between 
the nursing staff and the logistics support service provider in health care", Human Factors and Ergonomics in Manufacturing E Service Industries, Vol. 28 No. 3, pp. 117-129.

Komulainen, H. and Saraniemi, S. (2019), "Customer centricity in mobile banking: a customer experience perspective", International Fournal of Bank Marketing, Vol. 37 No. 5, pp. 1082-1102.

Kotavaara, O., Pohjosenperä, T., Juga, J. and Rusanen, J. (2017), "Accessibility in designing centralised warehousing: case of health care logistics in Northern Finland", Applied Geography, Vol. 84, pp. 83-92.

Kovács, G. and Spens, K.M. (2005), "Abductive reasoning in logistics research", International fournal of Physical Distribution \& Logistics Management, Vol. 35 No. 2, pp. 132-144.

Kumar, A., Ozdamar, L. and Ning Zhang, C. (2008), "Supply chain redesign in the health care industry of Singapore," supply chain management", Supply Chain Management: An International fournal, Vol. 13 No. 2, pp. 95-103.

Landry, S. and Philippe, R. (2004), "How logistics can service health care", Supply Chain Forum: An International fournal, Vol. 5 No. 2, pp. 24-30.

Langley, C.J., Jr. and Holcomb, M.C. (1992), "Creating logistics customer value”, fournal of Business Logistics, Vol. 13 No. 2, pp. 1-27.

Ledlow, G.R., Manrodt, K.B. and Schott, D.E. (2017), Health Care Supply Chain Management: Elements, Operations and Strategies, Jones \& Bartlett Learning, Burlington, MA.

Lehtimäki, T., Komulainen, H., Oinonen, M. and Salo, J. (2018), "The value of long-term co-innovation relationships: experiential approach", International Fournal of Business Innovation and Research, Vol. 16 No. 1, pp. 1-23.

Louise Barriball, K. and While, A. (1994), "Collecting data using a semi-structured interview: a discussion paper", Fournal of Advanced Nursing, Vol. 19 No. 2, pp. 328-335.

Moons, K., Waeyenbergh, G. and Pintelon, L. (2019), "Measuring the logistics performance of internal hospital supply chains-a literature study", Omega, Vol. 82 No. 82, pp. 205-217.

Olsson, O., Wiger, M. and Aronsson, H. (2014), "Developments in the field of health care logistics and SCM: a patient flow focus", in the 26th Conference of the Nordic Logistics Research Network, Copenhagen, Denmark, 2014, Copenhagen Business School, Denmark, pp. 409-422.

Orton, J.D. (1997), "From inductive to iterative grounded theory: zipping the gap between process theory and process data", Scandinavian Fournal of Management, Vol. 13 No. 4, pp. 419-438.

Plé, L. (2017), "Why do we need research on value codestruction?", fournal of Creating Value, Vol. 3 No. 2, pp. 162-169.

Plé, L. and Chumpitaz Cáceres, R. (2010), "Not always cocreation: introducing interactional co-destruction of value in service-dominant logic", fournal of Services Marketing, Vol. 24 No. 6, pp. 430-437.

Pohjosenperä, T., Kekkonen, P., Pekkarinen, S. and Juga, J. (2018), "Service modularity in managing health care logistics", The International fournal of Logistics Management, Vol. 30 No. 1, pp. 174-194.

Poulin, E. (2003), "Benchmarking the hospital logistics process: a potential cure for the ailing health care sector", CMA Management, Vol. 77 No. 1, pp. 20-23.

Rivard-Royer, H., Landry, S. and Beaulieu, M. (2002), "Hybrid stockless: a case study: lessons for health-care supply chain integration", International fournal of Operations E Production Management, Vol. 22 No. 4, pp. 412-424.

Shapiro, R.D. and Heskett, J.L. (1985), Logistics Strategy: Cases and Concepts, West Group, St Paul, MN.

Sorrentino, M., De Marco, M. and Rossignoli, C. (2016), "Health care co-production: co-creation of value in flexible boundary spheres", Proceedings of International Conference on Exploring Services Science, pp. 649-659.

Stewart, D.W. and Shamdasani, P.N. (2014), Focus Groups: Theory and Practice, Vol. 20, Sage Publications, Thousand Oaks, CA.

Vargo, S.L. (2008), "Customer integration and value creation: paradigmatic traps and perspectives", Fournal of Service Research, Vol. 11 No. 2, pp. 211-215.

Vargo, S.L. and Lusch, R.F. (2004), "Evolving to a new dominant logic for marketing", fournal of Marketing, Vol. 68 No. 1, pp. 1-17.

Vargo, S.L., Lusch, R.F. (2011), "It's all B2B ... and beyond: toward a systems perspective of the market", Industrial Marketing Management, Vol. 40 No. 2, pp. 181-187.

Vissers, J. and Beech, R. (2005), Health Operations Management: Patient Flow Logistics in Health Care, Routledge, New York, NY.

Volland, J., Fügener, A., Schoenfelder, J. and Brunner, J.O. (2017), "Material logistics in hospitals: a literature review", Omega, Vol. 69, pp. 82-101.

Wetter-Edman, K., Sangiorgi, D., Edvardsson, B., Holmlid, S., Grönroos, C. and Mattelmäki, T. (2014), "Design for value co-creation: exploring synergies between design for service and service logic", Service Science, Vol. 6 No. 2, pp. 106-121.

Yazdanparast, A., Manuj, I. and Swartz, S.M. (2010), "Cocreating logistics value: a service-dominant logic perspective", The International fournal of Logistics Management, Vol. 21 No. 3, pp. 375-403.

Yin, R.K. (2009), Case Study Research. Design and Methods, 4th ed., Sage Publications, Thousand Oaks, CA.

\section{Corresponding author}

Timo Pohjosenperä can be contacted at: timo. pohjosenpera@oulu.fi 